\title{
An investigation into the use of additive manufacture for the production of metallic bipolar plates for polymer electrolyte fuel cell stacks
}

\author{
Richard J. Dawson*, Anant J. Patel, Allan E.W. Rennie and Simon White \\ Engineering Department Lancaster University, Lancaster LA1 4YR, UK \\ *corresponding author
}

Tel: +44 (0) 1524593685

Email: r.dawson@lancaster.ac.uk

\begin{abstract}
The bipolar plate is of critical importance to the efficient and long lasting operation of a polymer electrolyte fuel cell (PEMFC) stack. With advances in membrane electrode assembly (MEA) design, greater attention has been focused on the bipolar plate and the important role it plays. Although carbon composite plates are a likely candidate for the mass introduction of fuel cells, it is metallic plates made from thin strip materials which could deliver significant advantages in terms of part cost, electrical performance and size. However, there are some disadvantages. Firstly, interfacial stability of the metal interconnect is difficult to achieve. Secondly, and the issue addressed here, is the difficultly and cost in developing new plate designs when there are very significant tooling costs associated with manufacture. The use of selective laser melting (SLM: an additive manufacturing technique) was explored to produce metallic bipolar plates for PEMFC as a route to inexpensively test several plate designs without committing to tooling. Crucial to this was proving that, electrically, bipolar plates fabricated by SLM behave similarly to those produced by conventional manufacturing techniques. This research presents the development of a small stack to compare the short term performance of metallic plates made by machining against those made by SLM. Experimental results demonstrate that the cell performance in this case was unaffected by the manufacturing method used and it is therefore concluded that additive manufacturing could be a very useful tool to aid the rapid development of metallic bipolar plate designs.
\end{abstract}

\section{Keywords}

Bipolar plate, Polymer electrolyte fuel cell, PEMFC, Selective laser melting, additive manufacturing 


\section{Introduction}

\subsection{Bipolar Plates}

The three main functions of bipolar plates are:

1. to provide stable, low resistance electrical interconnection between cells;

2. to transport reactants and products to and from the MEAs allowing efficient and safe operation;

3. to aid with the thermal management of product sized stacks.

The bipolar plates most frequently used in PEMFCs can be classified into three broad types: nonporous graphite; conductive filled - polymer composites; and metallic plates. Non-porous graphite has been a traditional choice for bipolar plates as they have good electrical properties and can be machined easily on a small scale. The US Department of Energy (DoE) targets 30 USD / kW for automotive stacks at a volume cost based on 500,000 units per annum, each stack containing perhaps up to 100 bipolar plates [1]. At these volumes, non-porous graphite is prohibitively expensive. This is where polymer composites seek to provide a solution which maintains the same level of functional fulfilment as the non-porous graphite but allow scalable manufacture through known processes such as injection moulding. To this end, many researchers have investigated exact filler and polymer combinations seeking optimum performance [2-4]. Hermann et al. [5] listed several combinations of polymer matrix composites with metallic or carbon based fillers, but it is carbon based plates which have received the most attention due to cost and strength issues. Kakati et al. [4] demonstrate that a good performance plate can be made using a combination of natural graphite, carbon black and carbon fibre fillers. Although these plates could fulfil the targets, the presence of high filler content renders the moulding process difficult and the end product is susceptible to low strength and anisotropic properties. The potential advantages of pressed metal plates are outlined in Table 1.

\section{TABLE 1 HERE}

The major disadvantage of metallic bipolar plates which has largely stopped them being a properly competitive selection is corrosion resistance, particularly in the acidic and oxidising environment of the cathode compartment. Antunes et al. [6] presents an extensive review of candidate steel corrosion data in acidic conditions showing that bare metal corrosion rates are significant. At the interface between the gas diffusion layer (GDL) and bipolar plate, this causes two unwanted effects. These are an increase in contact resistance due to passivating scale build up and a release of metal ions which migrate into the membrane reducing its conductivity. Progress is being made in the development of surface treatments such as electrochemical treatments to enrich the $\mathrm{Cr}$ and $\mathrm{Ni}$ content of the surface as demonstrated by Gabreab et al. [7] and physical treatments such as plasma nitriding as demonstrated by Omrani et al. [8] who show significant improvement in both corrosion resistance 
and interfacial contact resistance. A promising commercial solution to the problem is precoating strip steel to form a corrosion resistant barrier which also has a low interfacial resistance. Commercial coating lines for continuous strip processing are available at major steel producers such as Sandvik AG and are much more cost effective than post-coating individual complex parts when volumes are significant [9]. . When developing a fuel cell stack, simulation can be used to guide the designs but confidence, particularly for the purposes of investment in further development, is gained through successful demonstration. To commit to a design and produce tooling for bipolar plates usually costs in excess of 200,000 €. Processes such as continuous sheet metal hydroforming as being developed by Borit BV can reduce development costs but are still expensive. This tooling cost also precludes researchers in academia from being involved directly with pressed metal bipolar plates without significant industrial input, which could limit the scope of research. In the research reported here, the use of SLM is investigated to produce metallic bipolar plates for PEMFC as a route to provide inexpensive prototypes of several plate designs without committing to tooling. It is important to prove that electrically, bipolar plates made by SLM behave similarly to those made by conventional techniques. If plates made by SLM can be demonstrated to have the same performance, then there is great potential for reducing the cost of plate design and increasing the rate of development of novel plates. The use of additive manufacture may not be at a stage of development suitable for mass manufacture however, it could prove an enabling technology that greatly reduces the design cycle time and risk associated with development of commercial stacks. The importance of developing technologies which enable the introduction of 'cleaner' and more efficient energy conversion devices is high. If the example is taken of a fuel cell micro-CHP system, a target market for many PEMFC developers, then the UK market alone is worth around 1.5 M units per year [10]

\subsection{Selective Laser Melting (SLM)}

SLM is an additive manufacturing technique whereby the energy from a laser is directed to the surface of a bed of powder and thereby used to build up a three-dimensional (3D) structure in a layerwise manner, one layer at a time. It is particularly suited for bipolar plates as 316L and other stainless steels are commonly used to produce net shape products which are $98-99 \%$ dense. The process requires the generation of a 3D CAD model of the object to be produced which is then converted into the appropriate file format for uploading to the SLM machine. The orientation of the build is decided by the user along with other build file options such as the type and placement of support structures that might be required (to support overhanging features), laser power settings and laser scan speeds. The software then divides the object into uniform planar layers which will be sintered to progressively build the part. A simplified scheme for the process of building up the layers by selectively sintering the loose powder spread across the bed is given in Figure 1.

\section{FIGURE 1 HERE}


Kruth et al. [11] also provide a good overview for a number of the other metallic AM processes. Apart from the time to build, the major disadvantage of the process is the roughness of the surface finish produced which is of a size order dependent on the powder particle size used. This can be improved by a surface remelting process as shown by Yasa et al. [12] or also by mechanical finishing methods [13]. No tooling or jigging is needed to fabricate the part, but dependent on exact build configuration and geometry, support structures may be required that may also act as anchors for components on the build platen. The SLM machine employed in this study was a Realizer SLM 100, using a 316L SS powder with a nominal particle size $45 \mu \mathrm{m}$ giving an approximate layer thickness of $50 \mu \mathrm{m}$ during the build process.

\section{Stack Design and Manufacture}

It is possible to build sub-mm plate-like structures with SLM most easily by orienting the plate end-on (standing on an edge) although this is at the expense of build time as it increases the z-height of the build volume. However, since metal press tools and pressings are not financially viable in this study, a comparison between the performance of 316L SS milled plates of a suitable design are compared with the SLM version. The surface finish and porosity achieved in the resulting investigation is independent of the geometry and so the results of the comparison will still be valid against the overall objective. The stack design illustrated in the exploded side view of the 3D CAD model (designed using SolidWorks ${ }^{\mathrm{TM}}$ ) in Figure 2, is based on $5 \mathrm{~cm}^{2}$ active area cell, on $25 \mathrm{~cm}^{2}$ section of $50 \mu \mathrm{m}$ thick Nafion membrane as supplied by Paxitech (Echirolles, France, product code MEA S5-3L). The

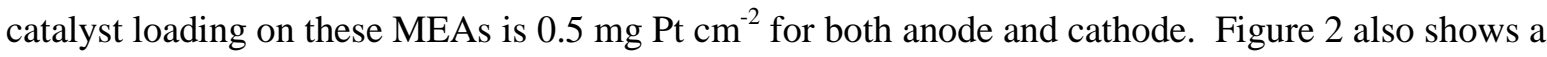
smaller scale 3D isometric view of the assembled rig as a two cell stack which clearly shows how the assembly plates with 4 off M5 studs apply compression to the stack and hold the assembly together.

\section{FIGURE 2 HERE}

Carbon fibre based GDLs are pressed into the active area to aid current collection and gas distribution. Gas seals are made from peroxide cured EPDM rubber sheet. Rebates are provided in the bipolar plates to locate the gaskets to prevent slippage and aid location. The depth and width of the rebates are sufficient to allow compression and good contact when using $0.5 \mathrm{~mm}$ thickness EPDM, and also space for the gasket to grow laterally during compression to prevent volumetric locking due to the value of Poisson's ratio for rubber being ca. 0.5 . Stack compression is maintained by external mild steel compression plates which also serve as current collectors from the cathode and anode endpoles. Shorting is avoided through the use of rubber sleeved studding and rubber washers. Nylon assembly pins are included within the perimeter of the bipolar plate design to provide repeatable location for the main stack components, though gasket placement and compression is assured through the gasket rebate in the design. Within the $5 \mathrm{~cm}^{2}$ active area and between the hydrogen inlet and outlet various 
fuel flow fields and associated current collection features were considered such as single / double serpentines, interdigitated and dimpled patterns. In each of these the channel widths were constrained to be no less than $1 \mathrm{~mm}$ in cross-sectional width due to the smallest size of cutting tool feasible for the CNC milling machine to be used. To help understand the likely resistive losses associated with the different designs an advanced engineering finite element package, Abaqus ${ }^{\mathrm{TM}}$ was used. Two example candidate flow fields and current collection designs, serpentine and dimpled, are shown in Figure 3.

\section{FIGURE 3 HERE}

A simple 3D representation of the anode, GDL and anode side of the interconnect was produced in the Abaqus environment. The GDL, interconnect and interface conductivities were defined, a uniform and arbitrary current density of $250 \mathrm{~mA} \mathrm{~cm}^{-2}$ was applied at the electrode (assuming uniform activity) and a potential sink term applied to the back of the interconnect. The software then solved the current and potential fields through the GDL, interface and interconnect and integrated the Joule heating $\left(\mathrm{I}^{2} \mathrm{R}\right)$ losses in the model. This loss calculated is for the current collection from one electrode. Given the current density, given the active area of $5 \mathrm{~cm}^{2}$, this loss can be easily translated into an ASR (area specific resistance) contribution to the overall cell ASR for the current collector design being considered. The GDL used was an Optiveil (Technical Fibre Products Ltd, Kendal, UK) non-woven carbon fibre laminate at $20 \mathrm{~g} \mathrm{~m}^{-2}$ sheet weight. This was treated with $3 \% \mathrm{wt}$ aqueous PTFE suspension (diluted from 60\%wt aqueous preparation code 665800, Sigma Aldrich UK) and into which a particulate carbon-based layer was calendared with a culinary dough roller (SP150, Imperia, Italy) giving an overall layer thickness of approximately $0.4 \mathrm{~mm}$. The dry composition of this particulate layer was 50\% wt carbon black (XC72R, Cabot Norit, Netherlands), $12.5 \%$ wt activated carbon (SX Ultra cat, Cabot Norit, Netherlands) and 37.5\% wt PTFE added as a 60\% wt aqueos suspension (code 665800, Sigma Aldrich, UK). Excess isopropyl alcohol was used as the solvent in the formation of this layer and subsequent calendaring which was removed by evaporation at room temperature overnight. The preparation of this layer is similar to that described by Bidault et al. [14] but modified for this application by the authors. The formed bi-layer was heat treated for $30 \mathrm{~min}$ at $250{ }^{\circ} \mathrm{C}$ to remove suspension surfactants and laminated at room temperature with the MEA at a pressure of 2.4 MPa using an Amsler 1076 tension / compression testing machine (Zwick/Roel, Germany). The conductivity of this layer was measured once formed using a 4 point measurement technique. Two pairs of thin nickel contacts were placed at opposite corners of the manufactured layer. Current was passed between one of each pair at opposite corners while the other two provided the potential probes. The impedance was measured with a Compactstat (Ivium, Netherlands) using the EIS (electrochemical impedance spectroscopy) functionality. This set up was then modelled as a homogenous layer of $0.4 \mathrm{~mm}$ within the Abaqus ${ }^{\mathrm{TM}}$ simulation environment to numerically solve the current field between the probes allowing for a representative value of $530 \mathrm{~S} \mathrm{~m}^{-1}$ for bulk conductivity 
for the laminate to be obtained. This value obtained is slightly reduced from the value quoted by the manufacturer for the carbon fibre cloth alone $\left(813 \mathrm{~S} \mathrm{~m}^{-1}\right)$ as the carbon black layer substantially loaded with PTFE will reduce the overall apparent conductivity of the laminate. For the purposes of the initial simulations, an interfacial contact resistance of $250 \mathrm{~m} \Omega \mathrm{cm}^{2}$ was taken between the 316L SS current collection features and the GDL. This was based on the work of Gabreab et al.[7] for untreated 316L SS and so represents the worst case scenario for contact resistance. The value of contact resistance experienced in the set up was later estimated from the impedance results when running fuel cells.

\section{FIGURE 4 HERE}

The local current densities predicted by Abaqus ${ }^{\mathrm{TM}}$ which dictate local resistive losses are shown in Figure 4 for the serpentine design and the dimple based design. Looking at this figure the larger areas of brightness around the dimple features in this design (lighter grey) indicates that there are areas of higher current density and consequently higher Joule heating losses in this design in the GDL and contacts. The difference in the losses between the two designs is particularly clear when the Joule heating losses integrated for the whole current collector are considered. Converting this loss to an ASR contribution using the current density simulated in the model, a contribution of $0.74 \Omega \mathrm{cm}^{2}$ for the serpentine design versus $1.51 \Omega \mathrm{cm}^{2}$ for the dimple design is obtained. For the air side, a $1 \mathrm{~mm}$ width rib current collection design, at a spacing of $1 \mathrm{~mm}$ was selected allowing for simple product water management, the ASR contribution of this was predicted to be around $0.73 \Omega \mathrm{cm}^{2}$ by the same methods. The air side design used can be seen in the image of the parts produced by SLM in Figure 5. The predicted ASR values for each of these cases are dominated by the contact area since the literature value used for the contact resistance in the simulation was high and dominates the losses experienced. If the DoE targets of $0.02 \Omega \mathrm{cm}^{2}$ for the interfacial losses [1] are to be achieved by 2017, then coatings or surface preparations such as those described by Gabreab et al. [7] which can achieve more than this target, will be required if low cost base steels such as 316 are to be used.

After considering the various designs compatible with the overall cell size, the single serpentine with channel section $1 \mathrm{~mm}$ square was selected. Even gas flows were predicted for both cells in the stack using Ansys Fluent ${ }^{\mathrm{TM}}$ computational fluid dynamics (CFD) which also demonstrated that there should not be any hydrogen maldistribution between the two cells even when both hydrogen flow and return were through the same compression plate giving a ' $U$ ' flow configuration in the stack. Ignoring consumption, the CFD predicted that a pressure drop of 11.2 mbar would be experienced across the plates at a flow rate of $21 \mathrm{ml} \mathrm{min}^{-1}$ with an imperceptible drop in the larger headers. The milling operation to produce the machined versions of the plates largely determined the overall plate thickness $(5 \mathrm{~mm})$ and the achievable channel size $(1 \mathrm{~mm})$. The milling process was conducted on a CNC milling machine (Bridgeport Interact 412, UK) using the same 3D CAD for components 
produced in the SLM machine. The plates as made by SLM showing both the air and fuel sides are shown in Figure 5. These clearly show the fuel serpentine, fuel inlet and outlet, gasket rebates, air channels and the holes required for the nylon assembly guides.

\section{FIGURE 5 HERE}

\section{Experimental Methods}

The experimental bipolar plates were manufactured by SLM and conventional CNC milling as described previously and surfaces carefully cleaned; SLM plates were wire brushed to remove loose powder particles and milled plates were washed down with acetone to remove the cutting coolant fluid residues. All plates were then gently surface polished on a polishing machine (Metkon Forcipol1) with 1200 grit SiC paper to remove any high spots or burs which would damage the MEAs. Before each experiment, the plates were gently sonicated in a small volume of acetone for 5 minutes to remove particles, fibres and any organics, thoroughly rinsed in $18 \mathrm{M} \Omega$ ultra-pure water (Millipore) and sonicated for a further 5 minutes. Plates were then dried for at least 20 minutes in a recirculating lab oven at $50{ }^{\circ} \mathrm{C}$ before assembly. The MEA and GDL combination was prepared by lamination at room temperature at a pressure of $2.4 \mathrm{MPa}$ as previously described and after the holes for the location pins had been carefully cut. The cells were then clamped together with a consistent torque of $3 \mathrm{Nm}$ applied to each M5 A4 Stainless steel nut on the A4 stainless steel studding leading to a consistent and uniform contact pressure. Care was taken to gradually increase the torque on the nuts in turn bringing the clamp plates together as near parallel as possible giving gradual and uniform compression up to the final torque achieved. The rig was then connected to a hydrogen supply flowing an excess of humid hydrogen from a PEM water electrolysis unit. This unit was made up of three parallel connected $5 \mathrm{~cm}^{2}$ active area PEM electrolysers (FCSU-010, Horizon fuel cells, USA) operating at a combined current of 5 A giving a hydrogen flow of approximately $35 \mathrm{sccm}$. Connection to the stack from the electrolyser was via Tygon tubing (St. Gobain, France) and a PFA range of pipe fittings (Swagelok, USA). For all experiments, a small sized fan from a computer CPU was used with a specially manufactured plenum and manifold to direct a consistent volume flow rate of air across the cathode side. This simple but effective air director can be seen in Figure 6 which shows the experimental setup during one run. Electrochemical measurements were made using a PGstat 30 potentiostat equipped with a frequency response analyser module (Metrohm, Autolab BV). After the hydrogen flow was commenced and the fan started, a stable open circuit potential was obtained each time and the cells then stabilised running at a constant current of $200 \mathrm{~mA}$ for 5 minutes to begin the hydration of the membrane. After this, a polarisation curve was run at a current scan rate of $2 \mathrm{~mA} \mathrm{~s}^{-1}$ down to a current of $1 \mathrm{~A}$. Two polarisation curves were conducted since no easily discernible change was observed between the second and subsequent scans. The slow scan rate used 
allowed the membrane to hydrate during the first scan so that stable performance could be obtained over the duration of the test. The cell was then returned to a constant load of $500 \mathrm{~mA}$ and allowed to stabilise before electrochemical impedance spectroscopy (EIS) measurements were taken at current point of $500 \mathrm{~mA}$ with a perturbation of $10 \mathrm{~mA}$. This ensured that the cell was running on the linear part of the polarisation curve, although linearity of response with perturbation depth was not specifically assessed. All experimental results presented here were obtained in a single 12 hour period such that any longer term changes to the plate surfaces would not be present or have an effect on the results. A consistent preparation, assembly and running method was applied each experiment such that it was the effect of performance due to differences between the two types of plates that was being evaluated.

\section{FIGURE 6 HERE}

\section{Results and Discussion}

Two single cell experiments were conducted for both machined and SLM plates using fresh MEAs each time. At the end of the single cell tests, a two cell stack was constructed from the SLM plates using the previously run MEAs. Two holes were cut in cell number 1 to allow hydrogen to flow through to cell number 2 . In all experiments, to reduce the likelihood of electrical shorting across the stack, current collection was via Ni strips direct onto the flow plates rather than from the compression plates. Voltage monitoring was conducted directly on the flow plates with separate wire connections to remove contributions from unwanted series resistances. Figure 7 shows the polarisation curves and Nyquist plots for the cell and stack that were obtained.

\section{FIGURE 7 HERE}

Good consistency between the measurements was achieved. The plates fabricated using SLM appear to perform as well as those made by machining with a very similar pure resistive content to the impedance indicating that the resistance due to current collection was very similar in each case. The single result for the two cell stack also shows twice the cell voltage and approximately twice the impedance giving confidence that the small stack design is working well without excessive problems with sealing or contact. Any slightly lower performance achieved in the 2 cell stack can be mostly attributed to the reuse of the MEAs from the single cell experiments. The comparatively low fuel flow rate (still around 5 times excess at $1 \mathrm{~A}$ ) which was the same for both the single cell and 2 cell stack experiments did not appear to cause any significant fuel starvation problems which would have been expected to be aggravated when running two cells. Considering the contact and GDL series resistances, the predicted ASR contributions from these sources for a single cell was $1.47 \Omega \mathrm{cm}^{2}$ whereas the experimental results which also include the membrane resistance are considerably better 
than expected. The impedance spectra indicate a purely resistive content of ca.0.052 $\Omega$ which based on the cell active area of $5 \mathrm{~cm}^{2}$ gives and ASR contribution of ca.0.26 $\Omega \mathrm{cm}^{2}$ each time. It is therefore very likely that the literature value for contact resistance is too conservative. By using the FEA model again to solve the current paths for the measured resistance, the results obtained here suggests that in both cases the contact resistance appears to be repeatedly about $37 \mathrm{~m} \Omega \mathrm{cm}^{-2}$. This is neglecting the contribution of the membrane resistance from the experimental results and assuming that the GDL laminate layer conductivity remains as measured. It also still assumes a completely uniform current density across the MEA. This coupled with the 3D nature of the electrode will mean that close to the interface with the MEA, some of the laminate resistance will begin to appear in parallel with the charge transfer resistance reducing slightly apparent series resistance contribution from the GDL [15]. In consideration of this, the contact resistance will still be considerably better than the initial figure used for the 316L and is likely due to the conformal nature of the fibre and particulate GDL and also due to significantly higher contact pressures between rib and GDL, being used here than the $1.4 \mathrm{MPa}$ used by Gabreab et al. [7]. Also in practice in the experimental set-up, there will be a slight increase in conductivity of the GDL under the ribs compared to the ex-situ measurement. This will be due to the local compression of the layer and can also account for some improved performance on what was predicted, however this effect will be comparatively small. Other authors report the use of much higher pressures and demonstrate greatly improved contact resistance less than $100 \mathrm{~m} \Omega \mathrm{cm}^{-2}$ [16]. Looking particularly at Figure 7B, it is apparent that the performance of the cells when using the SLM plates was slightly enhanced, evident in the smaller size of the arc and variation in the response at low frequency. Given the standard procedure used each time and assuming that the cells supplied and assembled with GDL are consistent, as the results would indicate, then it is likely that the subtle differences in the plates have had an effect on reactant transport. The rough surface of the SLM plates, which tend to give a slight corrugation across the rib since the plate is built in layers, will produce a less resistive reactant diffusion path under the contact ribs when the plates are assembled into the cell. This difference in surface topology between plates is illustrated in Figure 8 which shows a white light interferometry image of a rib feature made by SLM and a corresponding feature from the milled plates. These images were taken shortly after the testing had been conducted so are in the 'as tested' state. This figure shows that the SLM plates are rougher than their corresponding milled plate and have corrugations as illustrated by the white dotted lines, which are approximately perpendicular to the rib length and of a magnitude which is a function of the particle size of the powder used. There could also be an affect due to the rough channels causing turbulence and so greater transport rates, however, Reynolds numbers are low $(<10)$ so this is less likely.

\section{FIGURE 8 HERE}


The overall performance of the cells reported here are modest compared to those authors whose objective is high performance, and produce only ca. $200 \mathrm{~mA} \mathrm{~cm}^{-2}$ at a voltage of ca.0.5 V. However, the objective of this study was to demonstrate that performance is not adversely affected by the use of SLM to produce bipolar plates such that the technique can aid development before committing to costly tooling. Although limited, the consistency of the data obtained gives confidence that SLM will indeed be suitable. The ultimate desire of the continuation of this work will be to demonstrate that SLM can be used to produce thin form plates that accurately mimic the geometry (including complex radii) and features of plates made by metal pressing (made from 200-300 $\mu \mathrm{m}$ thin strip). Once his has been established the absolute performance will become much more critical and require the use of, for example, surface modification techniques to improve the plate performance and short term durability.

\section{Conclusions}

The experimental results reported here demonstrate the feasibility of using SLM for the production of prototype metallic bipolar plates for PEM fuel cells. The contact resistance and performance are shown to be the same as or slightly better than experienced when using plates of the same design but manufactured by a conventional machining process using a CNC milling machine. The use of SLM will allow different designs to be fabricated quickly with no tooling cost to give representative cell and stack performance at least over the short term so that novel plate design features can be rapidly assessed. Further work will be required to investigate the use of thinner light-weight designs representative of processes such as metal pressing.

\section{Acknowledgements}

The authors would like to thank the technical staff at Lancaster University, The Lloyds Register lab for loan of equipment and particularly Hassan Abou Ghazala for manufacturing the GDLs.

\section{References}

1. DoE (2013) Fuel Cell Technologies Office, Multi-Year Research, Development and Demonstration Plan. Department of Energy, USA

2. Dhakate SR, Mathur RB, Kakati BK, Dhami TL (2007) Properties of graphite-composite bipolar plate prepared by compression molding technique for PEM fuel cell. Int J Hydrogen Energ 32 (17):4537-4543. doi:http://dx.doi.org/10.1016/j.ijhydene.2007.02.017

3. Heinzel A, Mahlendorf F, Niemzig O, Kreuz C (2004) Injection moulded low cost bipolar plates for PEM fuel cells. J Power Sources 131 (1-2):35-40. doi:http://dx.doi.org/10.1016/j.jpowsour.2004.01.014

4. Kakati BK, Sathiyamoorthy D, Verma A (2010) Electrochemical and mechanical behavior of carbon composite bipolar plate for fuel cell. Int J Hydrogen Energ 35 (9):4185-4194. doi:http://dx.doi.org/10.1016/j.ijhydene.2010.02.033

5. Hermann A, Chaudhuri T, Spagnol P (2005) Bipolar plates for PEM fuel cells: A review. Int J Hydrogen Energ 30 (12):1297-1302. doi:http://dx.doi.org/10.1016/j.ijhydene.2005.04.016 
6. Antunes RA, Oliveira MCL, Ett G, Ett V (2010) Corrosion of metal bipolar plates for PEM fuel cells: A review. Int J Hydrogen Energ 35 (8):3632-3647.

doi:http://dx.doi.org/10.1016/j.ijhydene.2010.01.059

7. Gabreab EM, Hinds G, Fearn S, Hodgson D, Millichamp J, Shearing PR, Brett DJL (2014) An electrochemical treatment to improve corrosion and contact resistance of stainless steel bipolar plates used in polymer electrolyte fuel cells. J Power Sources 245 (0):1014-1026. doi:http://dx.doi.org/10.1016/i.jpowsour.2013.07.041

8. Omrani M, Habibi M, Amrollahi R, Khosravi A (2012) Improvement of corrosion and electrical conductivity of 316L stainless steel as bipolar plate by TiN nanoparticle implantation using plasma focus. Int J Hydrogen Energ 37 (19):14676-14686. doi:http://dx.doi.org/10.1016/j.ijhydene.2012.06.048

9. Lundberg MW, Berger R, Westlinder J, Folkeson N, Holmberg H (2013) Novel Multilayered PVDCoating in A Roll to Roll Mass Production Process. Solid Oxide Fuel Cells 13 (SOFC-XIII) 57 (1):2203-2208. doi:10.1149/05701.2203ecst

10. DECC UK Government (2013) The Future of Heating: Meeting the challenge.

11. Kruth JP, Levy G, Klocke F, Childs THC (2007) Consolidation phenomena in laser and powderbed based layered manufacturing. CIRP Annals - Manufacturing Technology 56 (2):730-759. doi:http://dx.doi.org/10.1016/i.cirp.2007.10.004

12. Yasa E, Kruth JP, Deckers J (2011) Manufacturing by combining Selective Laser Melting and Selective Laser Erosion/laser re-melting. CIRP Ann-manuf techn 60 (1):263-266. doi:http://dx.doi.org/10.1016/j.cirp.2011.03.063

13. Morton W, Green S, Rennie AEW, Abram TN Surface finishing techniques for SLM manufactured stainless steel 316L components. In: Bartolo PJ, DeLemos ACS, Tojeira APO et al. (eds) 5th International Conference on Advanced Research and Rapid Prototyping Leiria, Portugal, 2012. pp 503-509

14. Bidault F, Brett DJL, Middleton PH, Abson N, Brandon NP (2010) An improved cathode for alkaline fuel cells. Int J Hydrogen Energ 35 (4):1783-1788.

doi:http://dx.doi.org/10.1016/j.ijhydene.2009.12.035

15. Gomadam PM, Weidner JW (2005) Analysis of electrochemical impedance spectroscopy in proton exchange membrane fuel cells. International Journal of Energy Research 29 (12):11331151. doi:10.1002/er.1144

16. André J, Antoni L, Petit J-P, De Vito E, Montani A (2009) Electrical contact resistance between stainless steel bipolar plate and carbon felt in PEFC: A comprehensive study. Int J Hydrogen Energ 34 (7):3125-3133. doi:http://dx.doi.org/10.1016/i.ijhydene.2009.01.089

\section{Figure captions}

Table 1: Basic comparison of bipolar plates which can be used for volume production of PEMFC stacks. Specific mass is based on the mass per plate area for a generic design $1.5 \mathrm{~mm}$ thickness plate moulded or pressed from $0.2 \mathrm{~mm}$ Stainless Steel.

Figure 1: A simplified representation of the SLM process which builds up a part from fine metal powder which is laser sintered in distinct layers. A part is built progressively from a 3D CAD model with no tooling and little waste (unsintered powder is reclaimed and reused).

Figure 2: Side view of a 2 cell PEMFC prototype stack design in exploded view. This shows each of the critical components including the stack compression plates and studs. 
Figure 3: Flow domains for two candidate designs showing gas manifolds, location features and gasket rebates. The dimple design has a contact area of $1.21 \mathrm{~cm}^{2}$ whereas the serpentine design has an area of $2.41 \mathrm{~cm}^{2}$.

Figure 4: Current density distributions through the GDLs as predicted by Abaqus ${ }^{\mathrm{TM}}$ Finite Element Analysis (FEA) for a uniform cell current density of $250 \mathrm{~mA} \mathrm{~cm}^{-2}$ and a 316L SS current collector material for two designs. (A) dimpled current collection and (B) serpentine ribbed current collection. Brighter regions indicate higher current densities in these areas which result in higher Joule heating losses.

Figure 5: Photographs of anode and cathode side of the bipolar plate made by SLM. The serpentine was selected for the anode flow field whereas a simple straight channel and rib used on the air side. The slightly matt and speckled appearance of the plates is due to slight surface roughness (Ra values given in Figure 8) which is associated with the powder size used.

Figure 6: Photograph of setup for 1 cell when running at constant hydrogen supply of 35 sccm to the anode and consistent air supply to the cathode delivered by a by $12 \mathrm{~V}$ computer processor (CPU) fan. The fan is contained within the top of the air director on the top of the stack / cell and blows air down across the air sides of the cells.

Figure 7: (A) Polarisation curves for 4 individual single cells prepared, assembled and run by a consistent method using either all machined plates or all SLM plates and also for a 2 cell stack made of SLM plates. Current scan rate at $2 \mathrm{~mA} \mathrm{~s}^{-1}$. Curves shown are for second measurement taken. (B) Corresponding Nyquist plot of cell and stack impedance from $10 \mathrm{kHz}$ to $0.1 \mathrm{~Hz}$ taken at current point of $500 \mathrm{~mA}$ with a perturbation amplitude of $10 \mathrm{~mA}$. Fuel flow rates were $35 \mathrm{sccm}$ in all cases.

Figure 8: White light interferometer (Veeco Wyko NT1100) images for surface roughness for machined and SLM plates showing a section across an air side contact. Ra values are $2.3 \mu \mathrm{m}$ and 4.9 $\mu \mathrm{m}$ respectively. Plates are in the 'at tested' condition shortly after the cell testing had been completed. The white dotted lines on the image of the SLM rib highlight the ridges of the corrugations which are formed by the sintering of particles in a layer-by-layer process. 


\section{Figures}

Table 1:

\begin{tabular}{|l|l|l|}
\hline Property / Function & Polymer - carbon composite & Metallic (316L SS) \\
\hline Plate specific mass / $\mathrm{g} \mathrm{cm}^{-2}$ & 0.2 & 0.2 \\
\hline Bulk conductivity / $\mathrm{S} \mathrm{cm}^{-1}$ & $25-300$ & 13,500 \\
\hline Strength & Low & High \\
\hline Dimensional accuracy & Moderate & High \\
\hline Post machining requirement & Significant & Minor \\
\hline Cycle time (s) & Several & $<1$ \\
\hline Part complexity vs cost & $\begin{array}{l}\text { Increasing complexity such } \\
\text { as fineness of features } \\
\text { increases costs through more } \\
\text { runners, extra heated plates } \\
\text { and increased cycle time to } \\
\text { ensure mould is filled. }\end{array}$ & $\begin{array}{l}\text { Unlike injection moulding, } \\
\text { steel strip is not formed in a } \\
\text { single operation but at } \\
\text { several stations in a } \\
\text { progression tool. Increasing } \\
\text { complexity increases the tool } \\
\text { cost (length) but does not } \\
\text { increase cycle time. }\end{array}$ \\
\hline Recyclability & Difficult & Easy \\
\hline
\end{tabular}

Figure 1:

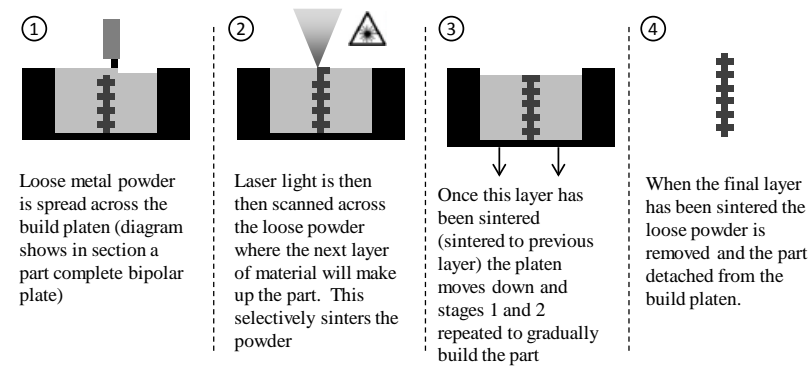

Figure 2:

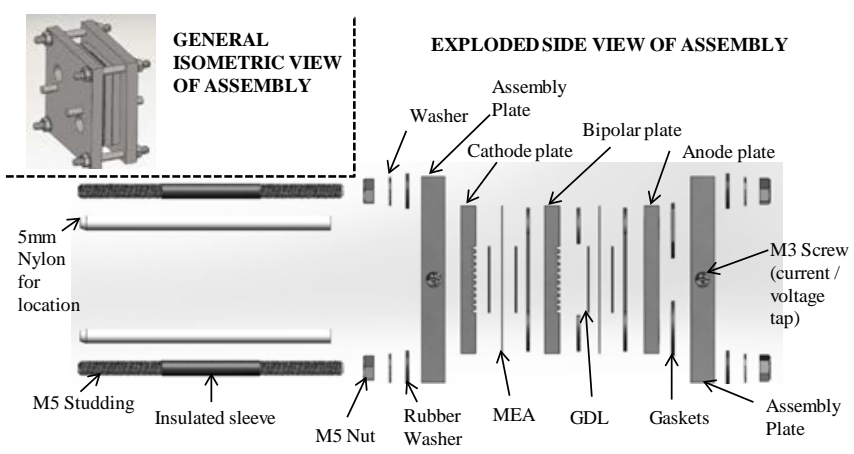

Figure 3: 


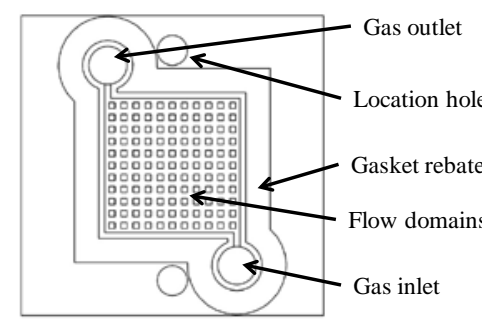

Closest spaced dimple design

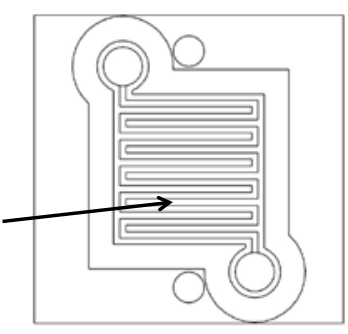

Serpentine design

Figure 4:

(A)

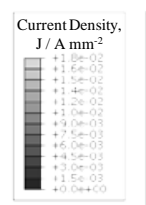

(B)

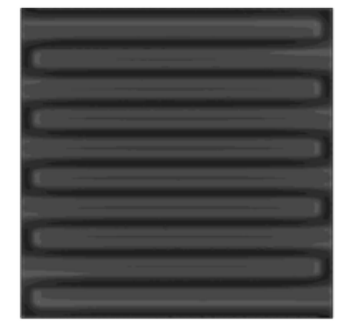

Figure 5:

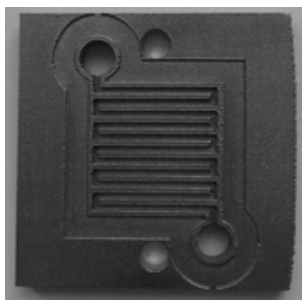

Anode Flow Field

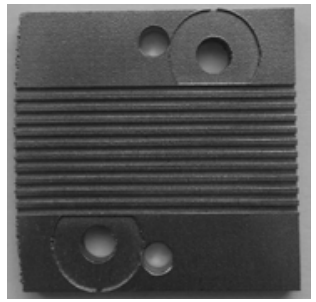

Cathode Flow Field

Figure 6

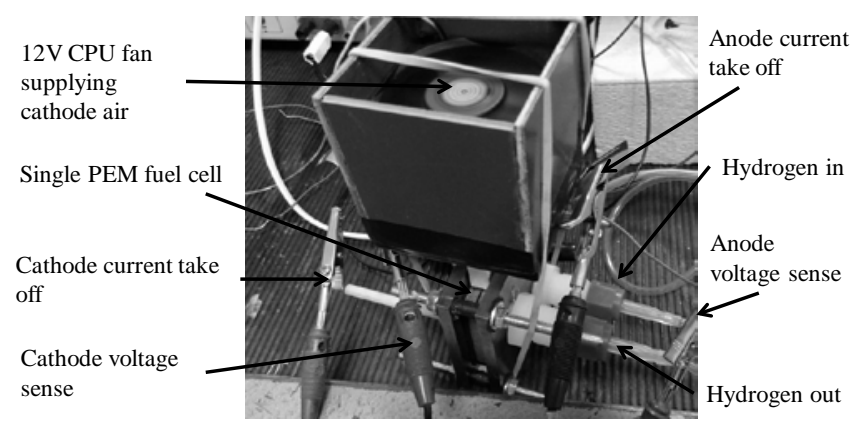

Figure 7: 

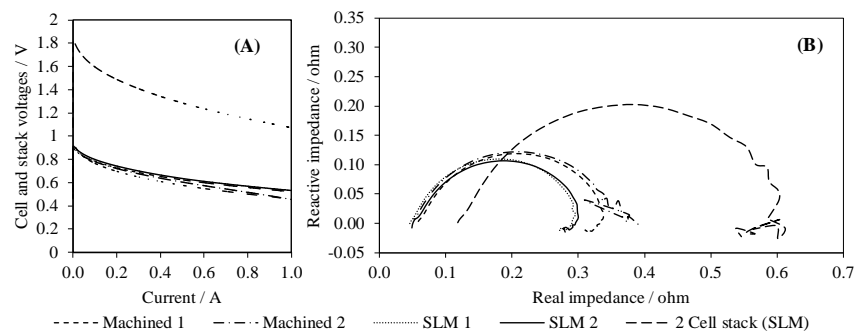

Figure 8:
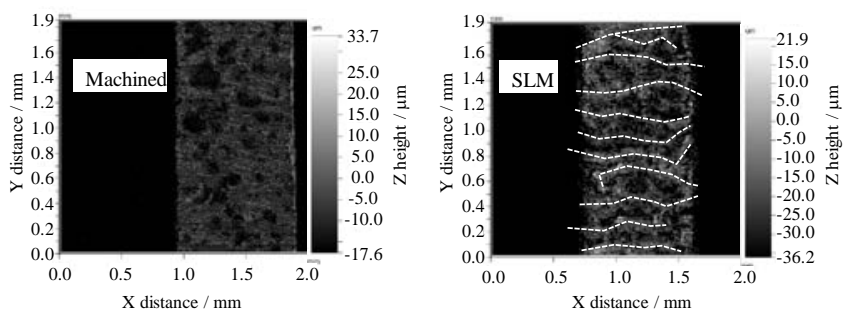